\title{
China spurs quest for human variome
}

Population giant weighs in with funds for disease-related genetics project.

\section{BY DAVID CYRANOSKI}

$\mathrm{T}$ he Human Variome Project (HVP), an ambitious initiative to uncover all of the genetic variations that cause human disease, received a massive boost last week when China announced that it would commit US $\$ 300$ million to the effort. The investment, to be paid out over ten years, puts the project on a firm footing for the first time since its launch in 2006, and signals China's intention to take on a bigger role in the medical-genetics field.

The sum is meant to cover roughly $25 \%$ of the cost of the HVP, a proportion matching China's share of the world's population and in keeping with its growing economic influence, says Ming Qi, director of the Zhejiang University Center for Genetic and Genomic Medicine, who has led the Chinese initiative. "With the state of our economic development, I felt we could do more," adds Qi.

As part of the agreement, announced on 21 January at the project's headquarters in

Melbourne, Australia, China will set up a genetics institute in Beijing to coordinate activities across the country and to give training in genetic counselling and testing. "The research will be very close to the clinic," says Qi. "It will be a fundamental change for China."

The HVP's goal is to establish "the standards, systems and infrastructure" that will allow sharing of disease-related genetic data between doctors and scientists throughout the world for use in diagnosis and research. Each participating country will have a network,

\section{"We want to collect every case of each disease."} or 'node', that collects information from diagnostic testing laboratories and hospitals.

Institutions that have signed up to help develop China's node include Peking Union Medical College Hospital, Tianjin Medical University Cancer Institute and Hospital and hospitals affiliated with Zhejiang University School of Medicine and Peking University. Qi envisages the funding bringing many more on board.

China's move offers not only financial resources but also greater access to a vast swathe of human genetic data from a part of the world previously under-represented in genetic studies. Five other nations are also developing nodes for the project - Australia, Kuwait, Malaysia, Egypt and Belgium. "We hope the commitment from the Chinese government will also highlight the need for this work to other countries and their funding bodies," says Richard Cotton, a geneticist at the University of Melbourne and head of the project's coordinating office.

Although other projects, such as the International HapMap Project, have assembled data on single nucleotide polymorphisms - common genetic variations across populations - the HVP is collecting information on all genetic variations related to human disease, including new and rare mutations, large-scale deletions and copy number variations. "We're casting our net wider," says Cotton. "We want to collect every case of each disease." - 